\title{
Corporate listening: Unlocking insights from VOC, VOE and VOS for mutual benefits
}

\author{
Jim Macnamara \\ University of Technology Sydney
}

\begin{abstract}
Purpose - While the voice of customers, employees, and other stakeholders have been identified as key components of corporate and marketing communication, comparatively little attention has been paid to how organizations listen to, make sense of, and use information provided. Research reported in this article examined how a multinational corporation and its subsidiaries listen to their customers, employees, and other stakeholders and explored how corporate listening can be improved for mutual benefits.
\end{abstract}

Design/methodology/approach - This article reports participatory action research within a multinational corporation operating in Europe, Canada and Australia which set out to become a 'listening organization' to improve its relationships and performance. The research was informed by interviews, observation, content analysis of relevant documents, and critical reflection.

Findings - This analysis illustrates the need for and benefits of looking beyond statistical data to analyze textual, aural and visual data available from call centers, open-end survey comments, complaints, correspondence, social media and other sources, and it identifies methods, tools and technologies for ethical insightful corporate listening.

Research implications - This article advocates a 'turn' from focus on voice to focus on listening, noting that expression of the voice of customers, employees, and other stakeholders has no value to them or organizations without active listening.

Originality - This paper reports an in-depth study of corporate listening to multiple stakeholders and identifies opportunities for increased insights and understanding that can lead to tangible benefits for both organizations and their stakeholders.

Keywords - Corporate listening, stakeholder engagement, voice of customers, voice of employees, voice of stakeholders.

Paper type - Research paper. 


\section{Voice - A source of feedback, insights and intelligence}

This analysis presents the findings of an extensive empirical study of voice in the context of corporate communication and how effective comprehensive corporate listening can provide valuable insights and tangible benefits for both organizations and stakeholders.

In addition to recognition of the role and importance of the voice of people generally in democratic politics and society (Couldry, 2010; Dobson, 2014), the voice of customers (VOC) is recognized as important in marketing and corporate communication. As Aguwa et al. (2017) say, the voice of customers is a valuable input that describes their needs and expectations for products and services. As such, VOC is a key source of insights and intelligence as well as feedback for organizations marketing products and services. Customer insights and feedback are collected through market research, customer satisfaction surveys, net promoter score (NPS) surveys, and mechanisms such as customer councils (Hill and Alexander, 2017), and are spontaneously provided through calls to call centers, complaints, website and social media comments, and other channels. Marketers recognize that such information can inform product, service and process design and improvement, which can ultimately lead to competitive advantage.

Also, the voice of employees (VOE) has gained considerable attention, with management and human resource literature showing that employee voice is directly connected to organizational engagement, satisfaction, loyalty, retention and productivity (Bashshur, 2015; Ruck et al., 2017). Employee voice is studied in human resource management (Conway et al., 2016), organizational communication (Edmondson, 2007), and organizational behaviour (OB) disciplines, as well as in an integrated way drawing on all of these fields of research (Mowbray et al., 2014).

Numerous studies show that there are tangible bottom-line benefits and competitive advantages from increased employee engagement and satisfaction. One study reported that companies with engaged employees and customers are three times more profitable (Klie, 2014, para. 3). A Harvard Business Review survey found that $71 \%$ of participants rated "high level of employee engagement" as a factor most likely to bring business success, exceeded only by high levels of customer service and effective communication (Harvard Business School, 2013, p. 4). A recent study reported that 'employees' upward expression of challenging but constructive concerns or ideas on work-related issues can play a critical role in improving organizational effectiveness" (Ruck et al., 2017).

Forms of VOE vary widely, ranging from official channels such as union representations and work councils (Wilkinson et al., 2014, pp. 11-12) to institutionally organized employee communication such as staff satisfaction surveys, meetings, staff conferences, and intranets, as well as discretionary employee communication including 'suggestion box' submissions, grievances, and social media comments (Yeomans and Fitzpatrick, 2017).

Increasingly, practitioners and researchers are seeing VOC and VOE as interconnected rather than discrete areas of communication. An article in CRM Magazine noted that "employees - especially those in the customer contact centers - are often the first to interact with customers and shape how the customer perceives the company, the brand, and its products and services" (Klie, 2014, para. 4. Thus, Klie argues that VOC and VOE blend. Another more recent article agrees, stating: "Want to hear the voice of customers? Listen to your employees" (Warner, 2017, para. 6). The interconnection of VOC and VOE also has been identified in 
academic research, such as in studies of staff interaction with patients in hospitals by Lam and Mayer (2013), who linked hospital-level customer-focussed voice by employees to hospitallevel service performance. Dean (2007) found evidence that a customer orientation by call center employees contributed to customers' affective commitment and loyalty (Dean, 2007). Reed, Goolsby and Johnston (2016) concluded that listening to employees and customers provides an "integrated market-orientated system".

There is recognition in corporate communication and public relations literature that there are also other stakeholders (Freeman, 1984) in addition to customers and employees who exert influence on organizations and with whom organizations need to engage. These include business partners such as retailers, agents, and brokers; investors in the case of public companies; and local communities in many instances, all of which contribute to corporate reputation and operational success. Most organizations need to maintain positive relationships with a range of stakeholders in addition to employees and customers. Thus, it can be argued that the voice of stakeholders (VOS) is an appropriate consideration in addition to specific focus of the well-known concepts of VOC and VOE.

A widely used (albeit broad) definition of voice in the context of customers, employees, or other stakeholders of organizations was provided by Hirschman (1970), who described it as:

... any attempt at all to change, rather than to escape from, an objectionable state of affairs, whether through individual or collective petition to the management directly in charge, through appeal to a higher authority with the intention of forcing a change in management, or through various types of actions or protests, including those that are meant to mobilize public opinion. (p. 30)

Employee voice has been defined specifically as "providing workers as a group with a means of communicating with management" (Freeman and Medoff, 1984, p. 8), in particular, with "the ability to have meaningful input into decisions" (Budd 2004, p. 23) [emphasis added].

The preceding definition highlights that it is not the expression of voice that leads to benefits such as increased engagement, loyalty, satisfaction, and the contribution of useful insights and ideas; it is the receipt, processing, consideration of, and response to VOC, VOE and VOS that makes these meaningful. In fact, expression of voice without appropriate consideration and response can lead to negative effects such as criticism, disengagement, decreased productivity, and loss of customers and employees (Macnamara, 2016a). This leads to a second body of literature that, along with understanding of voice, framed the research reported here.

\section{Listening to give voice value}

An emergent body of literature has focussed on listening, initially in an interpersonal context and, more recently, in an organizational environment. A number of researchers have noted that there are many forms of fake listening such as pretend listening (Bussie, 2011, p. 31) and pseudolistening (Adler and Rodman, 2011, p. 136) that do not provide meaningful input or lead to response. While organizational listening has unique characteristics, which are examined in the following analysis, the body of literature on interpersonal listening is informative in defining listening. Drawing on interpersonal listening, psychology, and ethics literature, Macnamara (2016a) proposed "seven canons of listening" (p. 41), which were used as the basis 
of evaluating listening in this study. These include recognition of others inclusively, rather than selective listening (Bickford, 1996; Honneth, 2007); acknowledgement of others' views and expressions of voice; paying attention to what others say (Bickford, 1996; Honneth, 2007, Husband, 2009, p. 441); and interpreting what others say as fairly and receptively in order to achieve understanding of others' views, perspectives, and feelings (Bodie and Crick, 2014; Husband, 1996). Based on openness and receptivity, listening then must involve consideration of what others say verbally or in text such as letters, submissions or complaints (Honneth, 2007; Husband, 2009) and responding in an appropriate way. Scholarship indicates that listening does not necessarily require agreement or acceptance of what is said or requested, but research shows that some response is required (Lundsteen, 1979; Purdy and Borisoff, 1997).

\section{Organizational listening-Scaling up, delegation, and mediation}

Organizations, particularly those with a large number of customers, employees, and other stakeholders, face particular challenges in listening, the first of which was noted by Dobson (2014) as the need for "scaling up" beyond one-to-one and small group methods of listening (pp. 75, 124). Large organizations are often expected to listen to thousands, hundreds of thousands, or even millions of voices in the form of VOC, VOE and VOS, as well as the voice of citizens, constituents or members in the case of government, non-government and political organizations.

Second, while interpersonal listening can be conducted in organizations' call centers, face-to-face meetings, and sales transactions, the voice of customers, employees, and other stakeholders is mediated through survey responses, focus group comments, letters, e-mails, website comments, and social media posts. Listening to these types of mediated voice requires the collection and analysis of various forms of textual, audio and, increasingly, video data. This highlights a key point that VOC, VOE and VOS are predominantly and most explicitly communicated in words, not statistics. For effective organizational listening to occur, management needs to understand that making sense from the growing phenomenon of 'big data' requires textual as well as statistical analysis.

Furthermore, even when interpersonal listening occurs in organizations, it is largely delegated to functions such as customer relations staff, call centers, complaints departments, and social media monitoring staff. Listening by organization management depends on articulation of interpersonal and mediated VOC, VOE and VOS by various functional units through reports, analyses, and presentations.

Therefore, organizational listening requires policies, processes, systems, resources and often technologies and related skills to conduct and articulate large-scale, delegated, mediated listening. A number of these requirements are addressed in organizational communication studies, although this discipline has largely focussed on interpersonal communication between management and employees, listening competency (Cooper and Husband, 1993), and relied heavily on structured surveys, which are increasingly seen as a limited method for listening to the voice of employees (Wiles, 2018). Gartner research predicts that almost $60 \%$ of organizations will use deeper levels engagement data from other sources and methods such as sentiment analysis in future (Wiles, 2018, para. 3).

In the era of online digital communication, natural language processing, machine learning content and textual analysis applications, voice to text (VTT) software, and other 
sense-making tools, expressions of voice can be listened to 24/7, compared with traditional customer and employee satisfaction or engagement surveys that are usually conducted only once a year.

The following analysis is informed by the concept of an 'architecture of listening' proposed in Macnamara (2016a, 2016b) based on empirical research in almost 40 organizations on three continents. This identifies eight elements that need to be in place for an organization to effectively engage with and benefit from VOC, VOE and VOS as follows:

1. A culture that is open to listening as defined by Honneth (2007) and Husband (1996, 2009;

2. Addressing the politics of listening, which can lead to selective listening and some groups being ignored;

3. Policies that specify and require listening in an organization;

4. Systems that are open and interactive, such as websites that allow visitors to post comments and questions and vote on others' comments;

5. Technologies that can aid large-scale listening, such as monitoring tools or services for tracking media and online comment, automated acknowledgement systems, and analysis tools for sense-making;

6. Resources including staff to operate listening systems and do the 'work of listening' (Macnamara, 2016a, pp. 51-52), such as monitoring, analyzing, and responding to comments, questions, complaints and suggestions;

7. Skills for large-scale organizational listening such as capabilities to undertake text analysis and social media analysis; and

8. Articulation of what is said to an organization to senior management in relevant areas such as product and service design.

Exploring how VOC, VOE and VOS can be encouraged, received and listened to effectively is an important field of study because of consistent evidence that active listening produces many benefits for organizations, customers, employees and other stakeholders. For example, Bentley (2010) reported that improving listening in an organization can have positive outcomes for customer satisfaction and even profitability of a business. Jenkins et al. (2013, p. xii) reported that companies that "listen to ... their audiences will thrive". Also, Yang et al. (2016 p. 189) reported that openness to stakeholders is "especially germane in engendering public trust". Organizational listening including corporate listening therefore warrants study.

\section{The Achmea strategy to become "a listening organization"}

Achmea is a multinational corporation operating in the insurance, pension and asset management sector, headquartered in the Netherlands with operating companies in Australia, Canada, Greece, Ireland, Turkey, and Slovakia. The group has more than 10 million customers and more than 15,000 staff in six countries. It sells life, health, motor vehicle, property, travel, and agricultural insurance online and through agents as well as independent brokers. Thus, it has a substantial number of customers, employees, and other stakeholders.

With premiums of more than $€ 20$ billion (euro) and assets under management of $€ 116$ billion (euro), the group is now the largest insurance provider in the Netherlands trading under 
brands including Zilveren Kruis and Centraal Beheer, as well as owning insurance market leaders including Interamerican in Greece; Eureko Sigorta in Turkey; Union poist'ovňa in Slovakia, Friends First in Ireland; Onlia in Canada; and Achmea Australia.

The author was invited to give a presentation to the group's annual CEO Summit held in Istanbul in early May 2017 and discuss how Achmea group companies could improve engagement with customers, employees, and other stakeholders with a view to increasing stakeholder understanding, satisfaction, and retention, which underpin organizational reputation and performance. Following the discussion, the CEOs of Achema operating companies agreed to fund a collaborative research project to identify ways to improve the group's capability as a "listening organization" through existing engagement activities and design and evaluate enhanced organizational listening capabilities (Achmea International, 2017).

\section{Research questions}

Based on the agreement adopted by the Achmea operating companies, the following research questions were developed for the project.

RQ1: How do the selected Achmea operating companies listen to their key stakeholdersspecifically, through which functional units and methods do the companies listen to their customers, employees, and other stakeholders such as agents?

RQ2: How can listening be improved and embedded in the culture and operations of the companies to gain increased insights and understanding of key stakeholders and improve performance and relationships?

RQ3: What benefits can be identified as a result of increased capacity and effectiveness in listening to customers, employees, and other stakeholders?

\section{Methodology}

Because the research required not only a review of existing methods of listening to key stakeholders, but implementation and evaluation of strategies to increase and improve the effectiveness of listening, action research was identified as the appropriate methodology. Furthermore, because such a project required cooperation and collaboration with managers and staff in a number of functional units in the participating companies, such as implementing and testing recommendations for organizational listening, participatory action research (PAR) was adopted as the overarching methodology.

Participatory action research involves exploration and interpretation by those involved in the actions studied and it takes places in the natural setting of the actions and processes being studied. Therefore, it is a qualitative methodology deployed within what is variously referred to as the interpretivist, constructivist, and naturalistic research paradigm.

An Open University guide provides a simple definition of action research as "any research into practice undertaken by those involved in that practice with an aim to change and improve it" (Open University, 2005, p. 4). Some regard all action research as participativethat is, it involves those responsible for the action or actions being studied in the research. For example, Dick describes the key characteristics or PAR as participative, qualitative, and 
reflective (2000, para. 3). However, whereas a studied group goes about its activities in the normal way in traditional action research (i.e., they do the actions and the researcher is responsible for conducting the research), in participatory action research the group being studied are co-researchers. Members of the studied group are encouraged to critically reflect on their actions (Dick, 2000) and engage in planning and implementing changes.

As well as studying listening in and by the Achmea International headquarters at Zeist in the Netherlands, three group operating companies were selected for study to gain a mix of Western European, Eastern European and 'New World' business and cultural perspectives: Interamerican headquartered in Athens, Greece; Union poist'ovňa headquartered in Bratislava, Slovakia; and Achmea Australia headquartered in Sydney.

\section{Methods}

Research methods used in participatory action research are typically ethnography (observation) supported by note taking or journaling, as well as interviews, and content analysis of relevant documents such as plans and reports, supported by critical reflection and evaluation of changes and initiatives implemented. The following methods were deployed in this study.

1. Semi-structured interviews were conducted with management, employees and other stakeholders to explore their experiences and views. Stage 1 involved 96 face-to-face interviews of 45 minutes to 1.5 hours duration. In Stage 3, a further 33 face-to-face interviews of 30 minutes to one hour were conducted with executives and staff responsible for key functions related to VOC, VOE and VOS - a total of 129 interviews. Also, five meetings with senior management were held to discuss progress of the research and review findings - a total of 134 personal discussions at a range of levels from CEOs and directors to data analysts and call center operators.

2. Content analysis was undertaken of a range of relevant documents. In Stage 1, 64 corporate documents and 75 website pages on seven corporate websites and e-commerce sites operated by the group were studied. In Stage 2, a further 24 documents were analyzed. These included strategic plans; operating plans; reports of customer and employee satisfaction surveys, Net Promoter Score (NPS) surveys, focus groups and other research; 'insight' reports from integrated data analysis and business intelligence units; reports and transcripts of call center operations; website feedback comments; and social media analyses.

3. Observation was conducted in the two largest operating companies, Interamerican and Union poist'ovňa, during two-week full-time visits in Stage 1, which included extensive informal discussion with actors in the processes examined and 'listening in' on activities such as call center processing of inquiries and complaints. Visits of 2-3 days were made to the Achmea International headquarters in the Netherlands and Achmea Australia in Stage 1 due to their smaller size in terms of staff and customer-facing operations. In Stage 2 , return visits of 2-4 days were made to the same sites. This period of observation was not sufficient to comprise ethnography, which involves study of "an intact cultural group in a natural setting over a prolonged period of time by collecting, primarily, observational and interview data" (Creswell, 2009, p. 13). Tedlock (2008, p. 151) says ethnographers 
need to live in a society for an extended period of time, which she cites as "two years ideally". However, these periods of first-hand observation of practices such as complaints processing, call center conversations, social media monitoring and response, and data analysis, in addition to interviews and content analysis of documents, contributed a significant level of what Geertz (1973) called "thick description."

After planning in the second half of 2017, the participatory action research project was undertaken in three stages. Stage 1 (January-March 2018) involved primary research to identify existing listening activities and gaps or opportunities for improvement. As is customary in PAR, findings and recommendations were shared with participants in presentations and meetings at the end of this period. Stage 2 (April 2018-May 2019) involved a 12-month period in which Achmea International and participating operating companies reviewed recommendations and implement changes and initiatives that were agreed. In Stage 3 (June-July 2019), a second round of primary research was conducted in Achmea International and participating operating companies to review and evaluate listening and engagement activities implemented. The findings reported here are primarily drawn from Stage 3 of the project.

\section{Data analysis}

Due to the large volume of interviews and lengthy discussions in many, full transcripts were not analyzed. Extensive notes were taken and analyzed using manual tagging and coding to categorize and identify key concepts and issues, which facilitated the identification of themes and consistent views (Krippendorff, 2013). Importantly, summaries of interviews were circulated to interviewees for review before drafting of the research report to correct any misunderstandings or significant omissions by the researcher. This helped ensure validity, which in qualitative research refers to authenticity, a fair and balanced approach, and plausibility. As Neuman (2006) says in Social Research Methods: Quantitative and Qualitative Approaches, "Authenticity means giving a fair, honest and balanced account of social life from the viewpoint of someone who lives it every day ... capturing an inside view and providing a detailed account of how those being studied understand events (p. 196) [original emphasis]. Review and confirmation of interview statements also helped ensure credibility, dependability and overall trustworthiness of the research, which research methods literature identifies as key criteria of qualitative research (Lincoln and Guba, 1985; Shenton (2004).

\section{Key findings—Sites, methods and benefits of active 'corporate listening'}

In accordance with emerging theory on organizational listening (Macnamara, 2016a), this research found that, while direct interpersonal listening to customers, employees and other stakeholders occurs in a large organization, delegated, mediated and scalable methods of listening are required to cope with the volume of information and feedback that is available.

\section{Sites of listening to customers, employees and other stakeholders}

From interviews and review of organizational structures, six key sites of potential direct listening to customers were identified in the Achmea operating companies studied. These are customer contact centers (generally referred to as call centers), which receive more than one 
million telephone calls a year in the companies studied; customer relations and customer relationship management (CRM) units in which staff respond to e-mails and letters and maintain records of customer interaction; complaints departments; marketing, which occasionally organizes customer events or meetings for direct communication; agents, who are key intermediaries between the companies and their customers; and branch and sales managers, who interact with agents and sometimes customers directly.

In addition, mediated listening to customers occurs through a range of departments, units, agencies, and mechanisms including market research coordinated by marketing, which undertakes customer satisfaction surveys, focus groups, user-testing (UX), and customer experience $(\mathrm{CX})$ research; business intelligence or insights units that synthesize and integrate data from multiple sources; website comments posted in 'contact us' pages or website feedback forms; and social media monitoring undertaken by digital communication staff, public relations, or external agencies.

Key sites of direct and mediated listening to employees in the Achmea operating companies studied are human resources (HR), which conducts annual employee engagement or satisfaction surveys and liaises with employees on a regular basis; intranets and special online platforms for employee suggestions, ideas and comments; internal communication staff employed in HR or public relations (PR), who are responsible for newsletters, employee events, intranets and online feedback platforms; and accelerator teams in which employees are invited to contribute to innovation in scrums (meetings) conducted as part of 'agile' management (Hobbs \& Petit, 2017).

In addition, other external stakeholders and partners such as agents, brokers and health care providers are engaged as part of stakeholder engagement as a specialist function in one of the operating companies studied.

Therefore, as reported above, there are 15 functional units or functions that interact with customers, employees, and other stakeholders in the companies studied and, through which, they have the capacity to listen, as well as disseminate information. Some corporations and major government organizations may have more. For example, government departments and agencies in many countries are required under regulations to engage with stakeholders through public consultation - albeit this is often done in tokenistic and 'tick a box' ways, and the findings are often ignored (Lane, 2015; Macnamara, 2017).

\section{Methods of listening in Achmea operating companies}

Almost three months of full-time research inside Achmea operating companies and the Achmea International office revealed a wide range of initiatives through which listening to customers, employees, and/or other stakeholders is undertaken. Because these are numerous, they are summarized in Table 1, after which a number of the most significant initiatives in terms of scale and innovation are discussed in detail. 
Table 1. Summary of key listening activities in Achmea operating companies.

\begin{tabular}{|c|c|c|}
\hline LISTENING METHOD & UNIT / SUPPLIER & IMPLEMENTATION \\
\hline \multicolumn{3}{|l|}{ CUSTOMERS: } \\
\hline $\begin{array}{l}\text { Recorded telephone calls from } \\
\text { customers; manual analysis }\end{array}$ & Customer Contact Centers & $\begin{array}{l}\text { Achmea Australia, } \\
\text { Interamerican; Union }\end{array}$ \\
\hline NPS surveys & MetrixLab & \multirow{2}{*}{$\begin{array}{l}\text { All operating companies } \\
\text { coordinated by head office }\end{array}$} \\
\hline $\begin{array}{l}\text { 'Closed loop' with call-backs to } \\
\text { 'detractors' }\end{array}$ & Customer Contact Centers & \\
\hline \multirow[t]{2}{*}{ Market research surveys } & Kynetic & \multirow{2}{*}{$\begin{array}{l}\text { Achmea Australia; } \\
\text { Interamerican; Union }\end{array}$} \\
\hline & Various suppliers & \\
\hline $\begin{array}{l}\text { User testing of proposed new } \\
\text { products }\end{array}$ & F2F meetings & Interamerican; Union \\
\hline Customer feedback on websites & Usabilla & Interamerican \\
\hline \multirow[t]{3}{*}{ Customer journey mapping } & Clientology & Union \\
\hline & Reframer & Interamerican (trialled) \\
\hline & Manually & Interamerican \\
\hline \multirow{3}{*}{$\begin{array}{l}\text { Textual analysis of open-end NPS } \\
\text { survey comments; written } \\
\text { complaints; e-mails from customers; } \\
\text { call center records }\end{array}$} & SAS Analytics & Interamerican \\
\hline & \multirow[t]{2}{*}{ Microsoft Power BI } & Interamerican \\
\hline & & Union trialling SAS Analytics \\
\hline $\begin{array}{l}\text { 'Deep dive' into NPS comments } \\
\text { using qualitative text analysis }\end{array}$ & Staffino (agency) & Union \\
\hline $\begin{array}{l}\text { Focus groups with customers, non- } \\
\text { customers and healthcare providers }\end{array}$ & Small group meetings & Interamerican; Union \\
\hline Customer event & F2F meeting & $\begin{array}{l}\text { Interamerican held one for } \\
500 \text { customers in } 2019\end{array}$ \\
\hline Customer Council & F2F meetings & Interamerican \\
\hline Customer Experience Board & F2F meetings & Union \\
\hline $\begin{array}{l}\text { Head of Business Intelligence / } \\
\text { Insights }\end{array}$ & Specialist position & $\begin{array}{l}\text { Union appointing August } \\
2019\end{array}$ \\
\hline Analytics Center of Excellence (ACE) & Head of ACE & $\begin{array}{l}\text { Interamerican, equivalent to } \\
\text { above }\end{array}$ \\
\hline Open Innovation Initiative & $\begin{array}{l}\text { Partnership in Athens } \\
\text { Center for } \\
\text { Entrepreneurship and } \\
\text { Innovation (ACEin) }\end{array}$ & Interamerican \\
\hline Integrated Insights Report & $\begin{array}{l}\text { Internal report combining } \\
\text { multiple data sets }\end{array}$ & Interamerican \\
\hline \multirow[t]{2}{*}{ Media monitoring } & C7EVEN & Achmea Australia \\
\hline & New Media Concept & Interamerican PR team \\
\hline
\end{tabular}




\begin{tabular}{|c|c|c|}
\hline Social media monitoring / analysis & $\begin{array}{l}\text { New Media Concept } \\
\text { (agency) }\end{array}$ & Interamerican \\
\hline \multicolumn{3}{|l|}{ EMPLOYEES: } \\
\hline Employee engagement survey & Effectory & $\begin{array}{l}\text { Achmea Australia; Union } \\
\text { Interamerican }\end{array}$ \\
\hline Interact & Custom intranet platform & Interamerican \\
\hline Staff intranet & Sharepoint & Union \\
\hline $\begin{array}{l}\text { Imagine Innovation Program } \\
\text { (see Open Innovation Initiative) }\end{array}$ & $\begin{array}{l}\text { Intranet platform to seek } \\
\text { ideas }\end{array}$ & Interamerican \\
\hline 'Town hall' meetings & Meetings & Union \\
\hline Staff meetings with Board members & Meetings & Union \\
\hline SmartUp teams & Meetings & Union innovation strategy \\
\hline Accelerator teams & Meetings & $\begin{array}{l}\text { Interamerican as part of } \\
\text { innovation strategy }\end{array}$ \\
\hline Internal social media & WhatsApp & Achmea Australia \\
\hline \multicolumn{3}{|c|}{ STAKEHOLDERS (e.g., agents, brokers, healthcare providers, etc.): } \\
\hline AskMe & Extranet for agents & Interamerican \\
\hline Agents' Council & Informal meetings & Interamerican \\
\hline $\begin{array}{l}\text { Focus groups with healthcare } \\
\text { providers }\end{array}$ & Small group meetings & Union \\
\hline $\begin{array}{l}\text { Stakeholder engagement / channel } \\
\text { management }\end{array}$ & $\begin{array}{l}\text { Informal meetings by } \\
\text { branch and sales staff }\end{array}$ & $\begin{array}{l}\text { Achmea Australia; } \\
\text { Interamerican; Union }\end{array}$ \\
\hline
\end{tabular}

The most significant initiatives that have been explicitly introduced for listening to customers, employees and/or other stakeholders in the Achmea group are as follows.

\section{Net promoter score (NPS) with a 'closed loop'}

Achmea has implemented net promoter score (NPS) surveys across the group following all customer interactions. Like many NPS surveys, in addition to the standard 0-10 scale for individual responses to the question: 'How likely are you to recommend [brand/product/service name] to your friends or colleagues', the customized NPS surveys implemented in Achmea operating companies include several open-end questions for customers to comment or provide explanation of their rating. Furthermore, a unique feature of the Achmea group NPS surveys provided by specialist service provide MetrixLab based in Rotterdam in the Netherlands (https://www.metrixlab.com), is that it includes what is referred to as a 'closed loop'. This involves outbound follow-up phone calls to detractors by operating company call centers to try to address their concerns. These calls involve active listening by specially trained call center operators.

While NPS surveys were introduced in the Achmea group prior to this research, callbacks to detractors were not being made by all operating companies during Stage 1. As part of this project it was agreed that the 'closed loop' should be applied more widely and, 
significantly, increased call-backs to detractors are proving to be highly effective in resolving customer concerns and turning detractors into passives, or even promoters, as well as increase overall NPS scores ${ }^{1}$. (See 'Evaluation of listening'.)

\section{Online listening tools}

In addition to the group-wide NPS surveys and other surveys to measure customer satisfaction and employee engagement, a number of other online listening technologies have been deployed in the Achmea operating companies during this project as a result of information sharing and collaboration. These include trials of the Usabilla application (https://usabilla.com) that provides a simple 'pop-up' mini-survey on websites for visitors to provide comments. A simple pop-up feedback form before exiting a website can capture instant visitor feedback.

Other online tools specifically designed for listening include intranets for employees (e.g., Interact in Interamerican and SharePoint in Union poist'ovňa), which include sections for staff comments; extranets such as the AskMe online platform for Interamerican agents; and the Imagine platform especially created by Interamerican to solicit ideas and suggestions for innovation and improvements in products and processes (see 'Innovative platforms - Internal and external').

\section{Textual analysis of open-end comments and written feedback}

As noted in the review of literature, listening involves analysis of comments - not only the capture or collection of VOC, VOE and VOS. Furthermore, as noted in defining organizational listening, textual as well as, or even more than, statistical analysis is required because customers, employees, and other stakeholders tell their stories predominantly in words, not numbers. Stage 1 of this research found that no textual analysis was being conducted by the Achmea operating companies studied, even though the group licenses SAS Analytics (https://www.sas.com/en_au/solutions/analytics.html), which in addition to powerful statistical analysis capabilities, includes tools for textual analysis (also referred to as content analysis and semantic analysis).

Based on recommendations in the Stage 1 research report, in 2019 Interamerican began extensively using the textual, contextual and sentiment analysis tools in SAS Analytics to identify the most frequently occurring terms and concepts in unstructured textual data and the sentiments expressed. Textual analysis is being applied in Interamerican to open-end comments provided in NPS surveys and other customer surveys; samples from approximately one million e-mails sent annually to the Customer Contact Center; written complaints; and notes recorded by Customer Contact Center staff in relation to telephone complaints. Union poist'ovňa commissioned an external agency, Staffino (https://staffino.com), to conduct 'deep dive' semantic analysis of open-end comments in its NPS surveys.

Textual analysis of comments in NPS surveys of Interamerican customers, for example, is able to identify the issues referred to most frequently by detractors, passives and promoters, as shown in Figure 1. This information informs management of the key problems to be addressed, as well as the main attributes that customers like, which need to be maintained. 
Figure 1. Leading issues cited by detractors, passives and promoters in Interamerican NPS surveys.

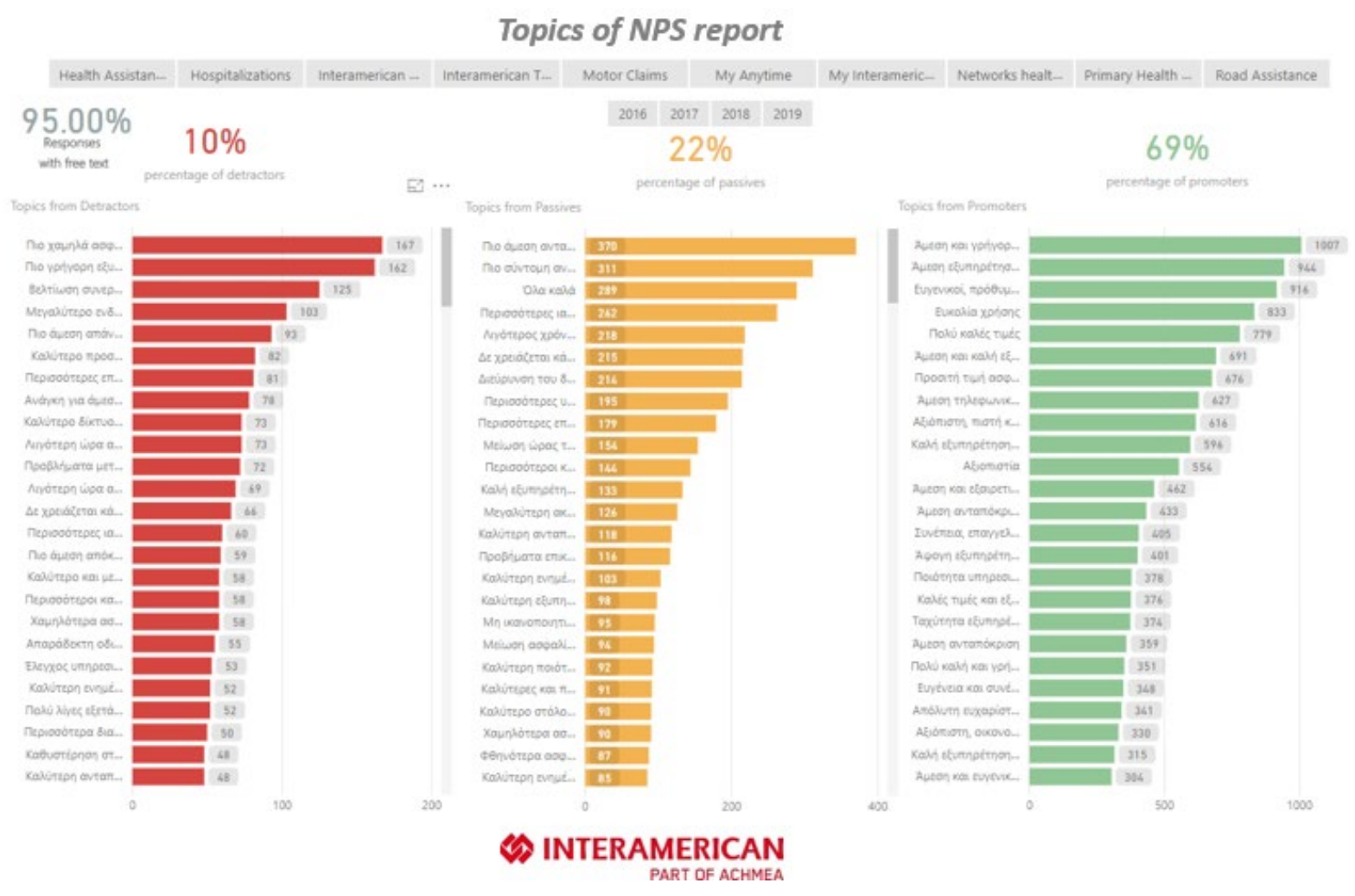

NOTE: Figure 1 is of low quality because it is a screen shot of actual data collected in this research project with text in Greek. It is presented for illustration purposes, not for reading.

In addition, the group has plans to introduce voice to text (VTT) software so that the one million plus telephone calls to operating company call centers, which are digitally recorded for quality purposes, can be translated into text and analyzed using textual analysis software. This will provide further insights into the concerns and interests of customers.

\section{Customer journey mapping}

In the first stage of this research, the Achmea operating companies studied were aware of customer journey mapping, also referred to as the customer decision journey (Court et al., 2009). However, none had implemented this method of tracking and evaluating the complete 'journey' and experience of customers from initial contact to post-sale engagements such as renewals and claims, as recommended by McKinsey consultants (Maechler et al., 2016). Tracking the complete journey and experience of customers, rather than a few selected 'touchpoints', provides a holistic understanding and ensures that all touchpoints that need to be improved are identified.

In 2019 Union poist'ovňa engaged a specialist supplier, Clientology from Belgium (https://clientology.be), to help it collect data and visualize its customer journey for various business units. CJM usually requires collection of a mix of quantitative and qualitative data from multiple customer touchpoints ranging from satisfaction with websites visited and call center inquires to the processing of claims. Union's marketing director said "we are in the early stages of development, with data collection in 2019, but full implementation is planned for 2020" (Anon, pers. comm., 13 June 2019). 


\section{Innovation platforms - Internal and external}

In addition to online platforms for communication, both Interamerican and Union poist'ovňa have launched initiatives to solicit ideas for innovation from employees, customers, and other stakeholders. The most substantial investment in this regard in the companies studied is the Open Innovation Initiative of Interamerican, which involves an internal online platforms for employee ideas (Imagine) and a major partnership with the Athens Center for Entrepreneurship and Innovation (ACEin). Prizes are offered as incentives for employees to submit ideas, with public recognition provided to those who ideas are adopted by a judging committee. As well as its SharePoint internal online platform, Union poist'ovňa has established what it calls SmartUp teams, a play on the term 'start-up' and the concept of accelerator teams used in promoting corporate innovation. These initiatives provide recognition to employees, customers, and other stakeholders as having valuable information and insights - the first principle in the 'seven canons of listening' (Honneth, 2007).

\section{Integrated insights reports}

A weakness identified in the research report from Stage 1 of this research was a lack of data integration in all of Achmea operating companies participating in the study. Various business units captured data ranging from statistical data such as financial, sales and demographic information to qualitative reports of focus groups, but there was no facility to combine data sets to form a more complete story. Also, the Stage 1 research identified a focus on statistics and a lack of qualitative data. One Business Intelligence staff member said: "We are mostly collecting tables of quantitative data" (Anon, pers. comm., 11 January 2018). A senior staff member involved in developing customer journey mapping said: "I don't have enough qualitative data" (Anon, pers. comm., 12 January 2018). This was addressed in 2018 and 2019 with the expansion of the Analytics Center for Excellence (ACE) in Interamerican, including the recruitment of additional data analysts (qualitative as well as quantitative). Union poist'ovňa approved the appointment of a Business Intelligence Manager to start in August 2019 to lead integration and mixed-method analysis.

\section{Face-to-face communication}

Despite a major commitment to adopting new technologies, including plans for automation of processes using artificial intelligence (AI) applications, the Achmea operating companies have not only maintained but increased their level of face-to-face communication with customers as well as agents. In early 2019, Interamerican held an event for 500 customers in Athens. This was used for gaining feedback on existing and proposed new products, as well as giving corporate presentations. Furthermore, Interamerican has established a Customer Experience Board, which involves invitations to a rotating group of customers to meet with company executives to discuss their experiences in dealing with the company and offer suggestions on improvements. An Interamerican manager said: "We get great feedback. We found out things that we didn't know" (Anon, pers. comm., 17 June 2019). Union poist'ovňa has similarly established a Customer Council.

Interamerican also has established an informal Agents Council at which company executive meet face-to-face with small groups of agents. Reflecting on the meetings with agents, an Interamerican executive said: "We were surprised. There were some things we 
thought were great, but the agents said, no, it was a problem" (Anon, pers. comm., 18 June 2019).

In Australia, following a devastating cyclone in 2017, senior executives of Achmea Australia travelled more than 1,000 kilometres to personally visit farmers whose crops had been destroyed and whose livelihood was dependent on prompt insurance payouts. A senior Achmea Australia executive said "This is a key part of the Achmea culture. We are people dealing with people" (Anon, pers. comm., 20 March 2018). Maintenance of personal contact despite the availability of automated telephone systems, bots, and AI systems is supported by research that shows "customers still want to talk to a human being" (Johnson, 2017, para. 1). This is a salient issue as corporations and governments rush to adopt increasing automation through AI.

\section{Evaluation of listening}

A key element of Stage 3 of this project was evaluation because, beyond operationalizing an 'architecture of listening', this research sought to identify benefits that accrue from corporate listening. Many factors influence outcomes and it is often difficult to attribute causality to particular initiatives and activities. However, in the following examples, the first criterion for establishing causality, temporal precedence, was clearly established. (i.e., the alleged causes preceded the effects reported). Second, covariation is evident, as the following metrics show variation in the dependent variables commensurate with manipulation of independent variables (the levels and types of listening). Ruling out other possible causes - the third criterion for establishing causality - is more difficult, but other potential causes were identified as far as possible. While not measured using controlled experiments, which are impractical in the naturalistic setting of a working corporate environment, some significant evidence of the "value of listening' was found, as reported in the following examples.

\section{NPS call-backs - Turning detractors into promoters}

The most specific and striking example of the value of listening resulted from the 'closed loop' NPS methodology implemented across Achmea operating companies during the period.

For example, after call-backs to almost $30 \%$ of more than 17,000 detractors of Interamerican, its online brand Anytime, and Union poist'ovňa in early 2018, a follow up NPS survey in March $2018(n=564)$ resulted in the NPS score increasing from -71 to +24 (van der Gouwe, 2018 , p. 3). During the first half of 2019, after call-backs to detractors, a follow up NPS survey sent to 586 detractors received 107 responses, of which 23 were converted to passives and 52 were converted to promoters. In short, almost $50 \%$ of detractors are being converted to promoters through call-backs to listen to their concerns, acknowledge them, and respond to them. The average NPS score of these detractors increased from -87 to +18 .

A senior marketing manager said "we can clearly see a monetary value in call-backs to detractors" (Anon, pers. comm., 19 June 2019), noting that converting detractors, who are likely to discontinue their custom in a competitive market, to passives or even promoters, creates a high probability of customer retention. Even if half of the $50 \%$ of detractors who are converted to promoters remain customers, based on a conservative customer lifetime value (CLV) of $€ 5,000$ (US\$5,500) in insurance premiums, this represents revenue of more than $€ 20$ million (US\$22.5 million). In comparison, the cost of call-backs to detractors is negligible, as existing call center staff make outbound calls when they are not busy with inbound calls. 


\section{Increased customer satisfaction and reduced complaints}

In both Interamerican and Union poist'ovňa customer satisfaction surveys show increases in 2018 and 2019 compared with previous years. More than $88 \%$ of Interamerican customers report that they are 'very satisfied' or 'satisfied'; 94\% of Anytime customers are satisfied with customer service; and 92\% are satisfied with Anytime telephone support. Customer complaints in Interamerican totalled a low $0.14 \%$ in 2018.

\section{Increased employee retention}

Interamerican had very low staff turnover rate of less than $1.5 \%$ in 2018 -i.e., very high employee retention. While economic conditions including high unemployment in Greece are likely to contribute to employees holding on to their jobs, Slovakia has a highly competitive employment market, yet employee retention in Union poist'ovňa increased in 2018 compared with 2017. This suggests that listening to employees has an effect on staff retention, which in turn reduces costs associated with recruitment and training. A senior Union poist'ovňa executive reflected:

Union is a better company than previously. We are operating in a traditional conservative market. There is limited talent to recruit with an almost zero unemployment rate in Slovakia. But I believe we are on track. We are ahead of the market now. (Anon, pers. comm., 14 June 2019)

\section{Discussion and conclusions}

Research shows that listening by organizations including corporations is under-studied and under-developed. In particular, listening to the voice of customers (VOC), employees (VOE), and other stakeholders (VOS) presents challenges because of scale; mediation through multiple forms of textual data such as letters, e-mails, open-end comments in surveys, website feedback forms, and social media posts as well as through interpersonal communication; and delegation to a range of functional units that need to process and articulate VOC, VOE and VOS to senior management.

However, empirical research reported here shows that listening actively and effectively to customers, employees, and other stakeholders affords opportunities and potentially significant financial as well as cultural benefits for organizations including corporations.

Furthermore, this research identifies a range of listening tools and systems that can enable large-scale listening to mediated voice, including computer-aided textual analysis that uses natural language processing and machine learning, as well as voice to text (VTT) software that can translate recorded telephone calls to call centers to text for analysis. It also draws attention to the need for data integration, including the synthesis of unstructured qualitative as well as structured quantitative data.

In addition, it identifies contemporary and emerging methods that facilitate insights from VOC, VOE and VOS, including call-backs to give attention, consideration, and respond to detractors identified in NPS surveys; customer journey mapping; online platforms to facilitate innovation through collaboration with employees and customers; and 'deep dive' qualitative research through focus groups, user-testing (UX), and customer experience (CX) studies. 
As such, this study offers important contributions to corporate communication theory and practice, as well as to and marketing communication. By identifying the importance of corporate listening - an element of corporate communication that hereto has received relatively little attention - this study points to a new direction in corporate communication research. It connects corporate communication to the large body of communication theory and research that emphasizes two-way communication, dialogue, and engagement. With active, effective corporate listening, corporate communication extends beyond one-way, top-down information dissemination and gains insights, understanding, and engagement that lead to trust, loyalty and sustainable relationships. Also through integrating insights from the voice of employees, customers, and other stakeholders, corporate listening reinforces corporate communication as representing the "organization as a whole" and as the function that incorporates internal and external communication, as proposed by Cornelissen $(2017$, p. 4$)$ and others.

\section{Acknowledgement}

This participatory action research project was funded by Achmea International, the Netherlands, and Achmea operating companies Achmea Australia, Interamerican in Greece, and Union poist'ovňa in Slovakia under a collaborative research contract and independently conducted under Human Research Ethics Committee approval (University of Technology Sydney Ref. No. ETH18-2924) and university research guidelines.

\section{References}

Achmea International. (2017), "Dreams paper", internal agreement, Zeist, the Netherlands.

Adler, R. and Rodman, G. (2011), Understanding Communication, 11th edn, Oxford University press, New York, NY.

Aguwa, H., Olya, M. and Monplaisir, L. (2017), "Modeling of fuzzy-based voice of customer for business decision analytics", Knowledge Based Systems, Vol. 125, pp. 136-45. DOI: https://doi.org/10.1016/j.knosys.2017.03.019

Bashshur, M. (2015), "When voice matters: A multilevel review of the impact of voice in organizations", Journal of Management, Vol. 41 No. 5, pp. 1530-54. DOI: https://doi.org/10.1177/0149206314558302

Bentley, S. (2010), “Listening practices: Are we getting any better?” in Wolvin, A. (Ed.), Listening and Human Communication in the $21^{\text {st }}$ Century, Wiley-Blackwell, Malden, MA, pp. 181-92.

Bickford, S. (1996), The Dissonance of Democracy: Listening, Conflict and Citizenship, Cornell University Press, Ithaca, New York, NY.

Bodie, G. and Crick, N. (2014), "Listening, hearing sensing: Three modes of being and the phenomenology of Charles Sanders Peirce", Communication Theory, Vol. 24 No. 2, pp. 105-23. DOI: https://doi.org/10.1111/comt.12032

Budd, J. (2004), Employment with a Human Face: Balancing Efficiency, Equity, and Voice, Cornell University Press, New York, NY.

Bussie, J. (2011), "Reconciled diversity: Reflections on our calling to embrace our religious neighbours", Intersections, Vol. 33, pp. 30-5.

Conway, E., Fu, N., Monks, K., Alfes, K. and Bailey, C. (2016), "Demands or resources? The relationship between HR practices, employee engagement, and emotional exhaustion within a hybrid model of employment relations", Human Resource Management, Vol. 55 No. 5, pp. 90117. DOI: https://doi.org/10.1002/hrm.21691 
Cooper, L. and Husband, R. (1993), "Developing a model of organizational listening competency", International Listening Association. Journal, Vol. 7 No. 1, pp. 6-34. DOI: https://doi.org/10.1080/10904018.1993.10499112

Cornelissen, J. (2017), Corporate Communications: A Guide to Theory and Practice, 5th edn, Sage, London, UK.

Court, D., Elzinga, D., Mulder, S. and Vetvik, O. (2009), "The consumer decision journey", McKinsey Quarterly, available at: http://www.mckinsey.com/business-functions/marketing-andsales/our-insights/the-consumer-decision-journey (accessed 14 May 2019).

Creswell, J (2009), Research Design: Qualitative, Quantitative and Mixed Methods Approaches, 3rd edn, Sage, Thousand Oaks, CA.

Couldry, N. (2010), Why Voice Matters: Culture and Politics after Neoliberalism, Sage, London, UK.

Dean, A. (2007), "The impact of the customer orientation of call center employees on customers' affective commitment and loyalty", Journal of Service Research, Vol. 10 No. 2, pp. 161-73. DOI: https://doi.org/10.1177/1094670507309650

Dick, B. (2000), A beginner's Guide to Action Research, available at: http://www.aral.com.au/resources/guide.html (accessed 16 May 2019).

Dobson, A. (2014), Listening for Democracy: Recognition, Representation, Reconciliation, Oxford University Press, Oxford, UK.

Edmondson, V. (2007), "Organizational surveys: A system for employee voice”, Journal of Applied Communication Research, Vol. 34 No. 4, pp. 307-310. DOI:

https://doi.org/10.1080/00909880600908526

Freeman, R. (1984), Strategic Management: A Stakeholder Approach, Pitman, London, UK.

Freeman, R. and Medoff, J. (1984), What Do Unions Do? Basic Books, New York, NY.

Geertz, C (1973). "Thick description: Toward an interpretive theory of culture", in C. Geertz, The Interpretation of Cultures: Selected Essays, Basic Books, New York, NY, pp. 3-30.

Harvard Business School. (2013), "The impact of employee engagement on performance", available at: https://hbr.org/resources/pdfs/comm/achievers/hbr_achievers_report_sep13.pdf (accessed 16 May 2019).

Hill, N. and Alexander, J. (2017), Handbook of Customer Satisfaction and Loyalty Measurement, 3rd edn, Routledge, London, UK.

Hirschman, A. (1970), Exit, Voice, and Loyalty: Responses to Decline in Firms, Organizations, and States. Cambridge, MA: Harvard University Press.

Hobbs, B. and Petit, Y. (2017), "Agile methods on large projects in large organizations", Project Management Journal, Vol 48 No 3, pp. 3-19. DOI: https://doi.org/10.1177/875697281704800301

Honneth, A. (2007), Disrespect, Polity, Cambridge, UK.

Husband, C. (1996), "The right to be understood: Conceiving the multi-ethnic public sphere", Innovation: The European Journal of Social Sciences, Vol. 9 No. 2, pp. 205-15. DOI: https://doi.org/10.1080/13511610.1996.9968484

Husband, C. (2000), "Media and the public sphere in multi-ethnic societies", in Cottle, S. (Ed.), Ethnic Minorities and the Media, Open University Press, Buckingham, UK, pp. 199-214.

Husband, C. (2009), "Commentary: Between listening and understanding”, Continuum: Journal of Media \& Cultural Studies, Vol. 23 No. 4, pp. 441-3. DOI: https://doi.org/10.1080/10304310903026602

Jenkins, H., Ford, S. and Green, J. (2013), Spreadable Media: Creating Value and Meaning in a Networked Culture, New York University Press, New York, NY.

Johnson, G. (2017), "Your customers still want to talk to a human being", Harvard Business Review, July 26, available at https://hbr.org/2017/07/your-customers-still-want-to-talk-to-a-human-being (accessed 12 July 2019). 
Klie, L. (2014), "When VoC and VoE combine", CRM Magazine, 1 September, available at: https://www.destinationcrm.com/Articles/Editorial/Magazine-Features/When-VoC-and-VoECombine-98709.aspx (accessed 18 May 2019).

Krippendorff, K. (2013), Content Analysis: An Introduction to its Methodology, 3rd edn, Sage, Thousand Oaks, CA.

Lane, A. (2015, May) Ticking the box and closing the loop: Can dialogue be mandated? Paper presented to the Annual Conference of the International Communication Association, San Juan, Puerto Rico.

Lincoln, Y. and Guba, E. (1985), Naturalistic Inquiry, Sage, Beverly Hills, CA.

Lam, C. and Mayer, D. (2013), "When do employees speak up for their customers? A model of voice in a customer service context," Personal Psychology, Vol. 67 No. 3, pp. 637-66. DOI: https://doi.org/10.1111/peps.12050

Lundsteen, S. (1979), Listening: Its Impact on Language and the Other Language Arts, ERIC Clearing House on Reading and Communication Skills, Urbana, IL

Macnamara, J. (2016a), Organizational Listening: The Missing Essential in Public Communication, Peter Lang, New York, NY.

Macnamara, J. (2016b), “The work and 'architecture of listening': Addressing gaps in organizationpublic communication”, International Journal of Strategic Communication, Vol. 10 No. 2, pp. 133-48. DOI: https://doi.org/10.1080/1553118X.2016.1147043

Macnamara, J. (2017), “Creating a 'democracy for everyone': Strategies for increasing listening and engagement by government', The London School of Economics and Political Science, available at http://www.lse.ac.uk/media@1se/research/CreatingADemocracyForEveryone.aspx (accessed 31 December 2019).

Maechler, N. Neher, K. and Park, R. (2016), "From touchpoints to journeys: Seeing the world as customers do", McKinsey \& Co., available at https://www.mckinsey.com/businessfunctions/marketing-and-sales/our-insights/from-touchpoints-to-journeys-seeing-the-world-ascustomers-do (accessed 12 July 2019).

Mowbray, P., Wilkinson, A. and Tse, H. (2014), “An integrative review of employee voice: Identifying a common conceptualization and research agenda", International Journal of Management Reviews, Vol. 17 No. 3, pp. 382-400, available at: https://doi.org/10.1111/ijmr.12045 (accessed 16 May 2019).

Neuman, W. (2006), Social Research Methods: Qualitative and Quantitative Approaches, 6th edn, Pearson, New York, NY.

Open University. (2005), Action Research: A Guide for Associate Lecturers, Center for OutcomesBased Education, Milton Keynes, UK, available at: $h$ http://www.open.edu/openlearnworks/course/view.php?id=1592 (accessed 12 July 2019).

Purdy, M. and Borisoff, D. (1997), Listening in Everyday Life: A Personal and Professional Approach, 2nd edn, University of America Press, Lanham, MA.

Reed, K., Goolsby, J. and Johnston, M. (2016), "Listening in and out: Listening to customers and employees to strengthen an integrated market-oriented system", Journal of Business Research, Vol. 69, pp. 3591-99. DOI: https://doi.org/10.1016/j.jbusres.2016.01.002

Ruck, K., Welsh, M. and Menara, B. (2017), "Employee voice: An antecedent to organizational engagement", Public Relations Review, Vol. 43 No. 5, pp. 904-14. DOI:

https://doi.org/10.1016/j.pubrev.2017.04.008

Shenton, A. (2004), "Strategies for ensuring trustworthiness in qualitative research projects", Education for Information, Vol. 22 No. 2, pp. 63-75. DOI: https://doi.org/10.3233/EFI-200422201 
Tedlock B (2008), "The observation of participation and the emergence of public ethnography" in Denzin, N. and Lincoln, Y. (Eds), Strategies of Qualitative Inquiry, 3rd edn, Sage, Thousand Oaks, CA, pp. 151-71.

van der Gouwe, P. (2018), “Achmea International: NPS closed loop feedback", research report, MetrixLab, Amsterdam, the Netherlands.

Warner, P. (2017), "Want to hear the voice of customers? Listen to your employees", CMS Wire, 27 September, available at: https://www.cmswire.com/customer-experience/want-to-hear-the-voiceof-customers-listen-to-your-employees (accessed 16 May 2019).

Wiles, J. (2018), "Is it time to toss out your old employee engagement survey?" Gartner, blog, 26 November, available at: https://www.gartner.com/smarterwithgartner/is-it-time-to-toss-out-yourold-employee-engagement-survey (accessed 16 May 2019).

Wilkinson, A., Dundon, J. Donaghey, T. and Freeman, R. (2014), "Employee voice: Charting new terrain", in Wilkinson, A., Dundon, J., Donaghey, T., and Freeman, R. (Eds), Handbook of Research on Employee Voice, Edward Elgar, Cheltenham, UK, pp. 3-16.

Yang, S., Kang, M. and Cha, H. (2015), "A study on dialogic communication, trust, and distrust: Testing a scale for measuring organization-public dialogic communication (OPDC)", Journal of Public Relations Research, Vol. 27 No. 2, pp. 175-92. DOI: https://doi.org/10.1080/1062726X.2015.1007998

Yeomans, L. and FitzPatrick, L. (2017). "Internal communication," in Tench, R. and Yeomans, L. (Eds), Exploring Public Relations, 4th edn., Pearson, Harlow, UK, pp. 286-307.

\section{Notes}

1 In NPS surveys, participants rate their likelihood to recommend an organization, product or service on a 0 10 scale, in which ratings of $9-10$ are regarded as 'promoters'; ratings of 7-8 are considered 'passive', and ratings of $0-6$ are described a 'detractors'. The overall NPS score is an index ranging from -100 to +100 , calculated by subtracting the percentage of detractors from the percentage of promoters. 